\title{
House Hold Remedies in Phosphide Poisoning
}

\author{
Dr. Avinash Shankar ${ }^{1 *}$, Dr. Amresh Shankar ${ }^{2}$, Dr. Anuradha Shankar ${ }^{3}$ \\ ${ }^{*}$ MBBS (MGIMS); MD (Internal Medicine); DNB (E\&M); PhD, Postgraduate in Endocrinology \& Metabolism \\ (AIIMS Delhi) Chairman National Institute of Health \& Research Warisaliganj (Nawada) Bihar, India \\ ${ }^{2}$ BAMS (BRABU); MHA, Director (Hon), AarogyamPunarjeevan Ram Bhawan, Ara Garden Road, \\ Jagdeopath, Bialy Road Patnal, India \\ ${ }^{3} B A M S$ (BRABU) Ex Director Centre for Indigenous Medicine \& Research Senior Research Fellow Regional \\ Institute of Ayurveda, Itanagar Arunachal Pradesh, India
}

*Corresponding Author: Dr. Avinash Shankar, BBS (MGIMS); MD (Internal Medicine); DNB (E\&M); PhD, Postgraduate in Endocrinology \& Metabolism (AIIMS Delhi) Chairman National Institute of Health \& Research Warisaliganj (Nawada) Bihar, India.

\begin{abstract}
Phosphide poisoning is known worldwide, especially in developing countries like India. It is being consumed frequently and exclusively for suicidal purpose. Among phosphide cereal preservatives (Aluminium phosphide-CELPHOS) and rodenticide (Zinc phosphide) are used quite rampantly. Considering the lethal outcome in patients remained untreated for longer duration, a measure to restrict release and absorption of phosphine various house hold measure being used, but majority i.e. - use of mustard oil, soap water and salt solution to induce emesis result in corrosive gastritis and bleeding which facilitate increased release and absorption of phosphine in turn increases toxicity and lethal outcome. Thus an awareness cum health education campaign was launched in 16 gram panchayat head quarter of Warisaliganj block of Nawada district of Bihar and educated through audio visual system to use Egg albumin Or Ghreet after any incident of phosphide poisoning (Aluminium phosphide Or Zinc phosphide) as early as possible and transfer the patient to appropriate centre for proper treatment .
\end{abstract}

Material \& Method: After this awareness program 1525 patients of phosphide consumption admitted at Centre for Critical Care, RA. Hospital\& Research Centre, Warisaliganj (Nawada) Bihar were considered, interrogated, clinically examined, investigated and duly treated.

Result: Out of all 1525 cases 945 cases have used either Egg albumin Or Ghreet within 1-2 hours and admitted at our centre within 3 hours of consumption, had complete recovery in $99.5 \%$ patient $(941 / 945$ )within 12 hours while other attending within same time and given similar treatment only 228(39.3\%) survived after rigorous and vigil observation for 36 hours but with altered haematological, hepatic, renal and neurological deficit .

Conclusion: Administration of Egg albumin Or Ghreet acting as physicochemical barrier restrict phosphide dissolution, release and absorption of phosphine as phosphide is non miscible to both , thus markedly improve therapeutic outcome .

Keywords: phosphide, aluminium phosphide, release, absorption

\section{INTRODUCTION}

Increasing financial constrain isolating family and increasing cost of day to day expenditure and intent to live lavishly generate stress and strain which ultimately leads to suicidal tendency and prompt consumption of easily available poison and common among them cereal preservatives or rodenticide, both phosphide i.e. Celphos (Aluminium phosphide) and rodenticide (Zinc phosphide $)^{1-5}$ which due to its lethal potency ensure death in majority cases who remained untreated for longer duration and presenting with agonising pain in abdomen, intense urge for water and black discoloration of blood ${ }^{6-8}$.

Aluminum phosphide poisoning is known worldwide especially in developing countries like India Lethal dose of ALP (aluminium phosphide) is 1-1.5 g. Deaths are reported even with a dose of 150$500 \mathrm{mg}$ when ingested liberates a lot of phosphine gas Which causes non competitive inhibition of the mitochondrial cytochrome oxidase blocks the electron transfer chain and oxidative phosphorylation, producing an energy crisis in the cells. The severe toxicity of ALP particularly 
affects the cardiac and vascular tissues which manifests as profound and refractory hypotension and congestive heart failure, metabolic acidosis is again common probably due to lactic acid accumulation as a result of inhibited oxidative phosphorylation and regressed tissue perfusion. Severity of metabolic acidosis is also a prognostic indicator in ALP (Aluminium phosphide) toxicity ${ }^{9-10}$

Prime motive of management is to ensure effective oxygenation, ventilation and circulation till complete neutralization and excretion of generated phosphine. Patients of severe phosphide poisoning need continuous and assured invasive hemodynamic monitoring and prompt early resuscitation with fluid and vasoactive agents. Specific measure against phosphide poisoning constitutes restricting release and absorption of generated phosphine, reducing cellular toxicity and increasing excretion through kidney and lungs ${ }^{11-13}$.

In vitro study affirm role of vegetable oils and liquid paraffin in restricting release and absorption of phosphine released on consumption of phosphide due to physiochemical properties of phosphide and no miscibility with fat . The mechanism by which coconut oil reduces the toxicity of phosphides was proposed that it forms a protective layer around the gastric mucosa, thereby preventing the absorption of phosphine gas Secondly it helps in diluting the $\mathrm{HCl}$ and again inhibiting the breakdown of phosphide from the pellet. Sodium-bicarbonate mainly neutralizes the $\mathrm{HCl}$ acid and thus diminishing the catalytic reaction of phosphide with $\mathrm{HCl}$, thereby inhibiting the release of phosphine. Medicated liquid paraffin or coconut oil should be given immediately after ALP ingestion ${ }^{14-16}$.

Majority patients were advocated oils and other fats to restrict the release and absorption of phosphine gas due to restricted dissolution of Aluminium phosphide and Zinc phosphide ${ }^{16-18}$ but use of mustard oil induces mucosal erosion and gastro intestinal bleeding and worsen the situation. Sometimes salt solution or Soap solution being used to induce emesis but results in corrosive gastritis and bleeding resulting in increased release and absorption of phosphine which form met haemoglobin and restrict oxygen transport ${ }^{18-20}$. Thus with intent to delay and decline dissolution of the consumed poison a house hold remedy i.e. - Egg albumin and ghreet been evaluated in patients consuming poison.

\subsection{Objective of Study}

To evaluate readily available house hold fat or egg albumin in delaying and declining dissolution of consumed poison for better outcome and post therapy quality of life .

\subsection{Duration of Study}

March 2012 to April 2018

\section{MATERIAL \& MethodS}

\subsection{Material}

Population of 16 gram panchayats of Warisaliganj Block of Nawada district of Bihar having risk of exposure to poison were considered.

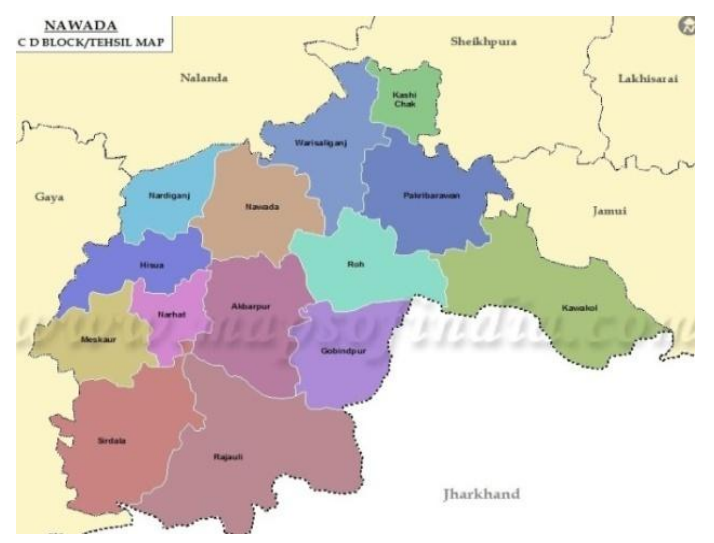

Gram Panchayats of Warisaliganj Block: Apsarh, Barnama, Baghibardiha, Chakwai, Dosuthajipur, Kochgaon, Kutri, Makanpur, Manjaur, Mosma Mohiuddinpur, Paingri, Shahpur, Saur, Thera 


\subsection{Method}

An education cum awareness program on declining fatality in persons consuming poison either accidentally or purposefully, was launched in the different panchayat headquarter of Warisaliganj (Nawada) Bihar with an audio visual screening, in addition patients were duly awared regarding agonising presentation and most encumbers therapeutic procedure and cost of treatment .

Gathering were duly explained regarding the uneventful agonising situation and outcome , methods to delay absorption and release of phosphine on ingestion by delaying and declining dissolution of the poison, so that by the time patients can reach appropriate centre to seek proper and expertise treatment to preserve their life and decline both morbidity, mortality and cost of therapy .

The Community were advised to administer -

- Egg albumin orally in non vegetarian

- Pure Ghreet in vegeterian orally within $1 / 2$ hour of ingestion Or as soon as possible

- Restrict use of mustard oil, soap solution and salt solution to induce emesis as it will increase absorption and permeability of blood vessels. During post awareness period patients admitted at our centre were interrogated for

- Post consumption use of adjuvant to induce emesis or delay absorption

- Use of any other substance to counter the poison

Admitted patients were interrogated, examined, Investigated and treated accordingly and result were observed. In post therapeutic stage patients were duly investigated for Serum phosphine, urine protein, blood urea, Serum creatinine and Hepatic profile, serum bilirubin, SGOT and SGPT.

In addition cost of therapy of patients who been advocated adjunct within 1 or $2 \mathrm{hr}$ of poison consumption versus others are compared to adjudge the adjunct significance in outcome and quality of life in patients of poisoning.

Table1. Clinical Grade and Characteristics

\begin{tabular}{|c|c|}
\hline Clinical grade & Characteristics \\
\hline Grade I & $\begin{array}{c}\text { Complete recovery without any residual , Adversity ,alteration in haematological, } \\
\text { Hepatic, renal or neurological parameters Within 12 hours of therapy }\end{array}$ \\
\hline Grade II & $\begin{array}{c}\text { Recovery with residual untoward effect And altered bio parameters with treatment for } \\
\text { more than 30 hrs }\end{array}$ \\
\hline Grade III & $\begin{array}{c}\text { Recovery with rigorous vigil observation and continued therapy for 36 hours and post } \\
\text { therapy follow up for 5 months for altered bio parameters }\end{array}$ \\
\hline
\end{tabular}

\section{RESULT}

Among the admitted 1525 patients of phosphide poisoning after awareness program from the area of coverage, $906(59.41 \%)$ were male and $619(40.59 \%)$ female. In addition $17.7 \%$ cases were of age group 15-20 years while $16.5 \%$ were of age group $40-45$ years (Table-2; Figure -1)

Table2. Distribution of Patients as Per Age \& Sex

\begin{tabular}{|c|c|c|c|c|}
\hline \multirow{2}{*}{$\begin{array}{c}\text { Age Group } \\
\text { (in years) }\end{array}$} & \multicolumn{3}{|c|}{ Number of patients } & \multirow{2}{*}{ Percentage } \\
\cline { 2 - 4 } & Male & Female & Total & \\
\hline $15-20$ & 182 & 88 & 270 & 17.7 \\
\hline $20-25$ & 128 & 136 & 264 & 17.3 \\
\hline $25-30$ & 112 & 104 & 216 & 14.2 \\
\hline $30-35$ & 182 & 109 & 291 & 19.1 \\
\hline $35-40$ & 117 & 110 & 227 & 14.9 \\
\hline $40-45$ & 185 & 72 & 257 & 16.8 \\
\hline Total & 906 & 619 & 1525 & \\
\hline
\end{tabular}




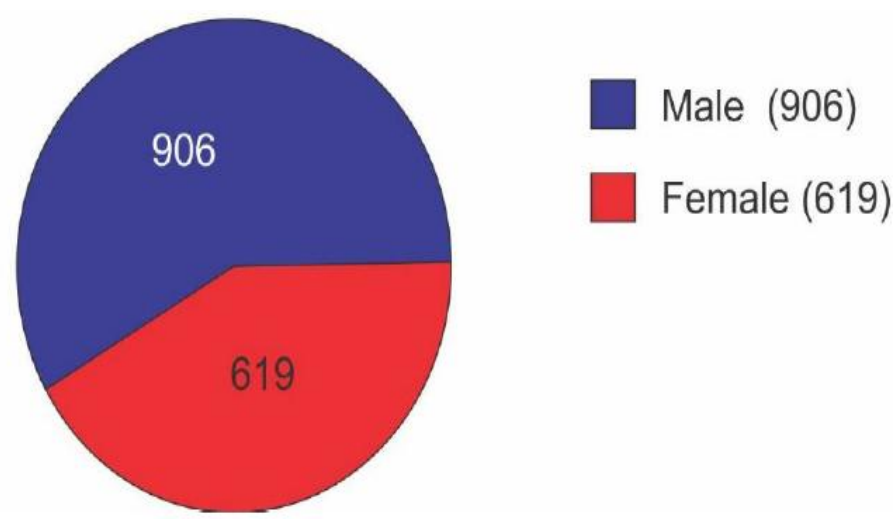

Figure1. Pie Diagram Showing Male Female Composition

Out of all $48 \%$ patients consumed supportive adjuvant therapy within $1 / 2 \mathrm{hr}$ of poison consumption while $4.9 \%$ after 2 hours of consumption (Table-3)

Table3. Distribution of Patients as Per Lag Period of Adjuvant Therapy

\begin{tabular}{|c|c|c|c|c|}
\hline \multirow{2}{*}{ Duration in Hours } & \multicolumn{3}{|c|}{ Number of patients } & \multirow{2}{*}{ Percentage } \\
\cline { 2 - 4 } & Male & Female & Total & 48 \\
\hline Within 1/2 & 419 & 312 & 731 & 26.8 \\
\hline $1 / 2-1$ & 280 & 128 & 408 & 15.6 \\
\hline $1-3 / 2$ & 132 & 106 & 238 & 4.7 \\
\hline $3 / 2-2$ & 46 & 27 & 73 & 4.9 \\
\hline$>2$ & 29 & 46 & 75 & \\
\hline
\end{tabular}

Out of all 998(65.4\%) and 527(34.6\%) have consumed Aluminium Phosphide and Zinc phosphide respectively (figure 2: pie diagram showing poison consumed)

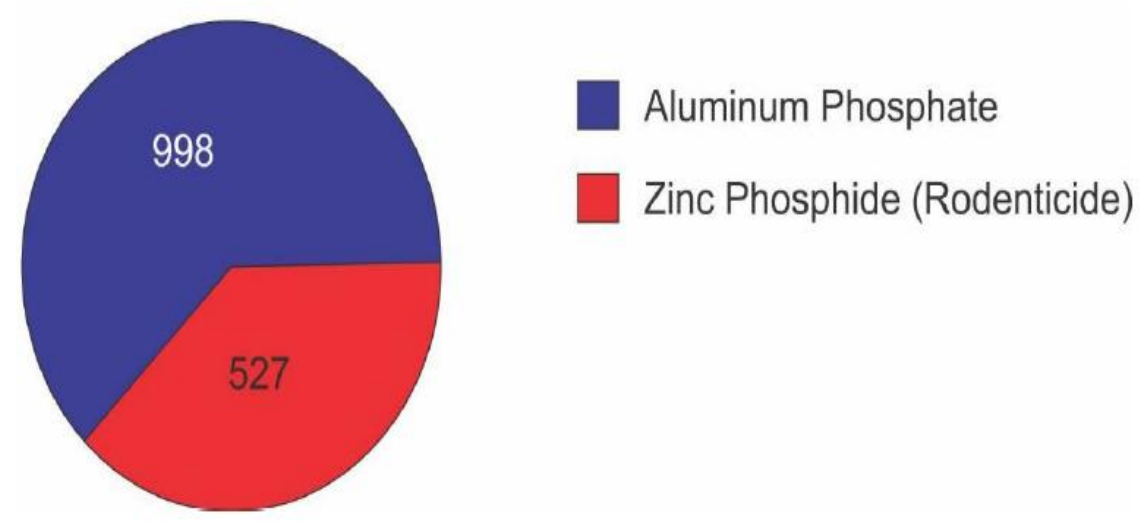

Figure2. Pie Diagram Composition of Patterns as Per Type Phosphate

Out of all 945(62\%) patients consumed awared house hold supplement i.e. - 396(26\%) Egg albumin and 549(36\%) ghreet while $580(38 \%)$ patients consumed other irrational house hold adjuvant (Table-4)

Table4. Distribution of Patients as Per Adjuvant Used

\begin{tabular}{|c|c|c|}
\hline Particulars & Number & Percentage \\
\hline Awared supplement (A) : & 945 & 62 \\
\hline Egg albumin & 396 & 26 \\
\hline Ghreet & 549 & 36 \\
\hline Other Suppliments (B) & 580 & 38 \\
\hline Mustard oil & 354 & 23.2 \\
\hline Soap water & 116 & 7.6 \\
\hline Salt solution & 100 & 7.2 \\
\hline
\end{tabular}

Though majority patients $85.7 \%$ at the time of admission were fully conscious and $14.3 \%$ were unconscious, $17.6 \%$ with agonising abdominal pain and $19.8 \%$ were carving for water (Table -5 ) 
Table5. Distribution of Patients as Per Clinical Status

\begin{tabular}{|c|c|c|c|c|}
\hline \multirow{2}{*}{ Particulars } & \multicolumn{3}{|c|}{ Number of patients } & \multirow{2}{*}{ Percentage } \\
\cline { 2 - 4 } & Group A & Group B & Total & 14.3 \\
\hline Unconscious & 68 & 150 & 218 & 85.7 \\
\hline Conscious & 877 & 430 & 1307 & 17.6 \\
\hline Agonising & 37 & 231 & 268 & 19.8 \\
\hline Carving for water & 48 & 254 & 302 & 6.7 \\
\hline Laboured breathing & 04 & 98 & 102 & \\
\hline
\end{tabular}

Among the admitted patients $6.8 \%$ were admitted within 1 hour of consumption while $13.5 \%$ were after $>3$ hours of consumption (Table-6)

Table6. Distribution of Patients as Per Lag Period

\begin{tabular}{|c|c|c|}
\hline Duration in Hours & Number of patients & Percentage \\
\hline Within 1 & 104 & 6.8 \\
\hline $\mathbf{1 - 2}$ & 288 & 18.9 \\
\hline $\mathbf{2 - 3}$ & 928 & 60.8 \\
\hline$>\mathbf{3}$ & 205 & 13.5 \\
\hline
\end{tabular}

Out of all 37, 48, and 04 patients taking awared supplement had agonising abdominal pain, crave for water and laboured breathing respectively while 231,254 and 98 patients taken other supplement had agonising abdominal pain, crave for water and laboured breathing respectively (Table- 7)

Table7. Outcome of Therapy

\begin{tabular}{|c|c|c|c|c|}
\hline \multirow[t]{2}{*}{ Particulars } & \multicolumn{4}{|c|}{ Number of patients } \\
\hline & Group A (945) & $\%$ & Group B (580) & $\%$ \\
\hline Survival : & 941 & 99.5 & 228 & 39.3 \\
\hline \multicolumn{5}{|c|}{ Post recovery Quality of life } \\
\hline Normal: & 941 & 99.5 & 27 & 4.6 \\
\hline \multicolumn{5}{|l|}{ With altered: } \\
\hline Haematological status & None & & 139 & 23.9 \\
\hline Hepatic status & None & & 126 & 21.7 \\
\hline Renal status & None & & 76 & 13.1 \\
\hline Neurological status & None & & 11 & 2.3 \\
\hline Mean recovery time: & 12 hours & & 36 hours & \\
\hline \multicolumn{5}{|l|}{ Clinical grade: } \\
\hline Grade I & & & 27 & 4.6 \\
\hline Grdae II & None & & 182 & 31.3 \\
\hline Grdae III & None & & 19 & 3.2 \\
\hline
\end{tabular}

99.5\% patients who consumed either egg albumin or ghreet as house hold supportive therapy had complete recovery without any alteration in haematological, hepatic and renal profile while other group only $39.3 \%$ patient recovered but with altered hepatic and renal profile ,. Cost of therapy in group A remain less than $40 \%$ of the other group

Patients of phosphide poisoning consuming Egg albumin Or Ghreet within 1Or 2 hrs of consumption of either Aluminium phosphide (Grain preservative -Commonly available CELPHOS) Or Zinc Phosphide (Rodenticide) and attended our Centre within 2 hours had outstanding clinical outcome and quality of life in $99.5 \%$ than group of patients who had taken other first aid supplement had survival in only in $39.3 \%$ with altered haematological, hepatic, renal and mental status.

\section{DISCUSSION}

Phosphide toxicity varies with post consumption use of supplement with an intent to restrict phosphide dissolution ,release and absorption of phosphine Phosphide affect Cellular respiration due to its effect on mitochondria ,inhibition of Cytochrome $\mathrm{C}$ oxidase, formation of highly reactive hydroxyl radicals ,Cellular injury due to lipid peroxidation, decrease level of catalase and increased superoxide dismutase activity , decline concentration of Glutathione in different tissues ${ }^{21-22}$

With an intent to decrease dissolution of consumed phosphide ,restrict release and absorption of phosphine, an awareness programm cum health education program been launched to use Egg albumin Or Ghreet after any misuse of phosphide, which ensured an excellent outcome in future incident of phosphide poisoning i.e.- 
Among admitted 1525 cases of phosphide poisoning 945 used the awared supplement i.e.- Egg albumin Or Ghreet within 1 hour of incident and attended the Centre within 2-3 hours shows survival rate of $99.5 \%$, with mean recovery time of 12 hours and grade I clinical outcome without any post therapy alteration in haematological, hepatic, renal and neurological bio parameters where as other supplement

Shows survival rate of $39.3 \%$, recovery time of 36 hours of rigorous vigil observation and critical care with altered haematological, hepatic, renal and neurological bio parameters and grade I recovery in only $4.6 \%$.( Figure 3 )

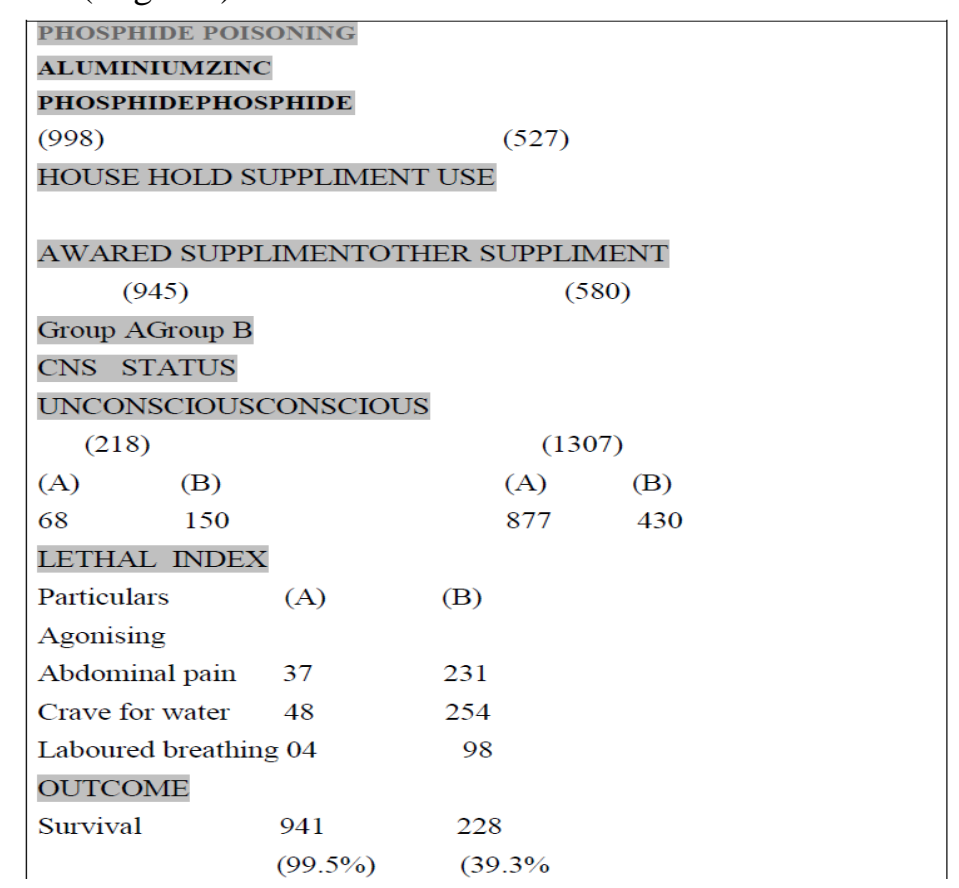

Figure3. Schematic Presentation of Status of Poisoning Patient

Egg albumin Or ghreet forms a physicochemical layer over the phosphide and due to non missibility prevent dissolution and hydration of phosphide thus restrict release of phosphine, coating over the GIT mucosa checks absorption while other supplement either forms a more lethal compound or prompt fast hydration, release of phosphine and increased absorption due to pronounced sodium potassium ATPase pump activity proves more fatal. (Figure 4)

\begin{tabular}{|c|c|c|}
\hline \multirow[t]{2}{*}{ Egg albumin } & & $\begin{array}{l}\text { OTHER SUPPLIMENT } \\
\text { Mustard Oil: }\end{array}$ \\
\hline & PHOSHIDE & More toxic , GI bleeding \\
\hline Ghreet & & $\begin{array}{l}\text { Soap Water : } \\
\text { increases phosphine } \\
\text { release }\end{array}$ \\
\hline Restrict dissolution of phosphide & & $\begin{array}{l}\text { Salt water: } \\
\text { pronounce dissolution, } \\
\text { increase release and } \\
\text { absorption of Phosphin by } \\
\text { activating }\end{array}$ \\
\hline Restrict release of Phoshin & & $\begin{array}{l}\text { Sodium Potassium ATPase } \\
\text { pump in GIT }\end{array}$ \\
\hline \multicolumn{3}{|l|}{ Restrict absorption of Phosphin } \\
\hline & Gastric lavage & \\
\hline $\begin{array}{l}\text { Facilitate removal of } \\
\text { Maximum toxins and } \\
\text { Ensure neutralisation } \\
\text { Of toxin by antidote }\end{array}$ & & $\begin{array}{l}\text { Removes only suppliment } \\
\text { not the toxin } \\
\text { toxin gets absorbed } \\
\text { and pose lethal fate }\end{array}$ \\
\hline
\end{tabular}

Figure4. Schematic Presentation of Effect of Post Consumption House Hold Supplements 


\section{CONCLUSION}

Administration of egg albumin or ghreet acting as physicochemical barrier restrict phosphide dissolution, release and absorption of phosphine as phosphide is non miscible to both thus markedly improve therapeutic outcome.

\section{ACKNOWLEDGEMENT}

The Organisation is very thankful to mukhiyas of various panchayat whose dedicated help ensured the success of the project.

\section{REFERENCES}

[1] Gunnell D, Eddleston M, Phillips MR, Konradsen F. The global distribution of fatal pesticide selfpoisoning: Systemic review. BMC Public Health. 2007; 7:357-71. [PMC free article] [PubMed]

[2] Eddleston M, Karalliedde L, Buckley N, Fernando R, Hutchinson G, Isbister G, et al. Pesticide poisoning in the developing world-a minimum pesticides list. Lancet. 2002; 360:1163-7. [PubMed]

[3] Gunnell D, Eddleston M. Suicide by intentional ingestion of pesticides: A continuing tragedy in developing countries. Int J Epidemiol. 2003; 32:902-9. [PMC free article] [PubMed]

[4] Siwach SB, Yadav DR, Arora B, Dalal S, Jagdish Acute aluminum phosphide poisoning - An epidemiological, clinical and histo-pathological study. J Assoc Physicians India. 1988; 36:594-6. [PubMed]

[5] Goel A, Aggarwal P. Pesticide poisoning. Natl Med J India. 2007; 20:182-91. [PubMed]

[6] Siwach SB, Jagdish K, Katyal VK, Dhall A, Bhardwaj G. Prognostic indices in aluminium phosphide poisoning: Observations on acidosis and central venous pressure. J Assoc Physicians India. 1997; 45:693-5.

[7] Louriz M, Dendane T, Abidi K, Madani N, Abouqal R, Zeggwagh AA. Prognostic factors of acute aluminum phosphide poisoning. Indian J Med Sci. 2009; 63:227-34. [PubMed]

[8] Bumbrah GS, Krishan K, Kanchan T, Sharma M, Sodhi GS. Phosphide poisoning: A review of literature. Forensic Sci Int. 2012; 214:1-6. [PubMed]

[9] Mishra UK, Tripathi AK, Pandey R, Bhargwa B: Acute phosphine poisoning following ingestion of aluminium phosphide. Hum Toxicol. 1988, 7: 343-345. 10.1177/096032718800700408.View Article PubMed Google Scholar

[10] Singh S, Dilawari JB, Vashist R, Malhotra HS, Sharma BK. Aluminium phosphide ingestion. Br Med J. 1985; 290:1110-1. [PMC free article] [PubMed]

[11] Bogle RG, Theron P, Brooks P, Dargan PI, Redhead J. Aluminium phosphide poisoning. Emerg Med J. 2006; 23:e3. [PMC free article] [PubMed]

[12] Tripathi SK, Gautam CS, Sharma PL. Clinical pharmacology of aluminium phosphide poisoning. Indian J Pharmacol. 1992; 24:134-7.

[13] Gupta S, Ahlawat SK. Aluminum phosphide poisoning-a review. J Toxicol ClinToxicol. 1995; 33:1924. [PubMed]

[14] Proudfoot AT. Aluminium and zinc phosphide poisoning. ClinToxicol (Phila) 2009;47:89100.[PubMed]

[15] Mehrpour O, Keyler D, Shadnia S. Comment on aluminium and zinc phosphide poisoning. ClinToxicol (Phila) 2009; 47:838-9. [PubMed]

[16] Wahab A, Zaheer MS, Wahab S, Khan RA. Acute aluminium phosphide poisoning: An update. Hong Kong J Emerg Med. 2008; 15:152-5.

[17] Bajpai SR: Aluminium phosphide poisoning: management and prevention. J Indian Acad Forensic Med. 2010, 32: 352-354.Google Scholar

[18] Khosla SN, Nand N, Khosla P: Aluminium phosphide poisoning. J Trop Med Hyg. 1988, 91: 196198.PubMedGoogle Scholar

[19] Vijay Kumar Agrawal, Abhishek Bansal, Ranjeet Kumar Singh, Bhanwar Lal Kumawat, and Parul Mahajan Aluminum phosphide poisoning: Possible role of supportive measures in the absence of specific antidote ,Indian J Crit Care Med. 2015 Feb; 19(2): 109-112.doi: [10.4103/0972-5229.151019]

[20] Gupta A, Beg M, Mohammed J, Azfar SF, Akhtar N. Coconut oil and aluminium phosphide poisoning. SAFCON-2007 South Asian and VII Annual Conference of Indian Congress Forensic Medicine and Toxicology; March 24-25, 2007. 
[21] Shadnia S, Rahimi M, Pajoumand A, Rasouli MH, Abdollahi M. Successful treatment of acute aluminium phosphide poisoning: Possible benefit of coconut oil. Hum ExpToxicol. 2005;24:2158.[PubMed]

[22] Jaiswal S, Verma RK, Tewari N. Aluminum phosphide poisoning: Effect of correction of severe metabolic acidosis on patient outcome. Indian J Crit Care Med. 2009; 13:21-4. [PMC free article][PubMed]

Citation: Dr. Avinash Shankar et al. "House Hold Remedies in Phosphide Poisoning", International Journal of Clinical Chemistry and Laboratory Medicine (IJCCLM), vol. 5, no.1, pp. 29-36, 2019. http://dx. doi.org/10.20431/2455-7153.0501005

Copyright: (c) 2019 Authors. This is an open-access article distributed under the terms of the Creative Commons Attribution License, which permits unrestricted use, distribution, and reproduction in any medium, provided the original author and source are credited. 